\title{
Paul ARNOULD, Laurent SIMON, Géographie de
}

l'environnement

Paris : Belin, Atouts géographie, 2007

\section{Jean-Pierre Husson}

\section{CpenEdition}

\section{Journals}

Édition électronique

URL : http://journals.openedition.org/rge/1325

DOI : $10.4000 /$ rge. 1325

ISSN : 2108-6478

Éditeur

Association des géographes de l'Est

Édition imprimée

Date de publication : 1 janvier 2008

ISSN : 0035-3213

\section{Référence électronique}

Jean-Pierre Husson, "Paul Arnould, Laurent simon, Géographie de l'environnement », Revue Géographique de l'Est [En ligne], vol. 48 / 1-2 | 2008, mis en ligne le 15 décembre 2009, consulté le 22 septembre 2020. URL : http://journals.openedition.org/rge/1325 ; DOI : https://doi.org/10.4000/rge.1325

Ce document a été généré automatiquement le 22 septembre 2020.

Tous droits réservés 


\section{Paul ARNOULD, Laurent SIMON, Géographie de l'environnement}

Paris : Belin, Atouts géographie, 2007

Jean-Pierre Husson

\section{RÉFÉRENCE}

Paul ARNOULD, Laurent SIMON, Géographie de l'environnement, Paris : Belin, Atouts géographie, 2007, $303 \mathrm{p}$. 
1 Formés à la biogéographie, les deux auteurs qui unissent ici leurs compétences et connivences scientifiques et didactiques apportent dans ce livre une contribution éclairée à propos des problèmes globaux posés par les dysfonctionnements récurrents de nos éco et sociosystèmes. A l'échelle globale, ces derniers évoluent à plusieurs vitesses. La planète s'avère plus malmenée et déménagée qu'aménagée de façon durable, prudente, raisonnée. La mesure holiste est indispensable pour apprécier les solidarités et tensions générées par la montée en puissance des effets de la mondialisation. Pour paraphraser Marcel Jollivet, ces auteurs sont des passeurs de frontières. Cela signifie qu'ils tissent des liens et du sens entre sciences de la
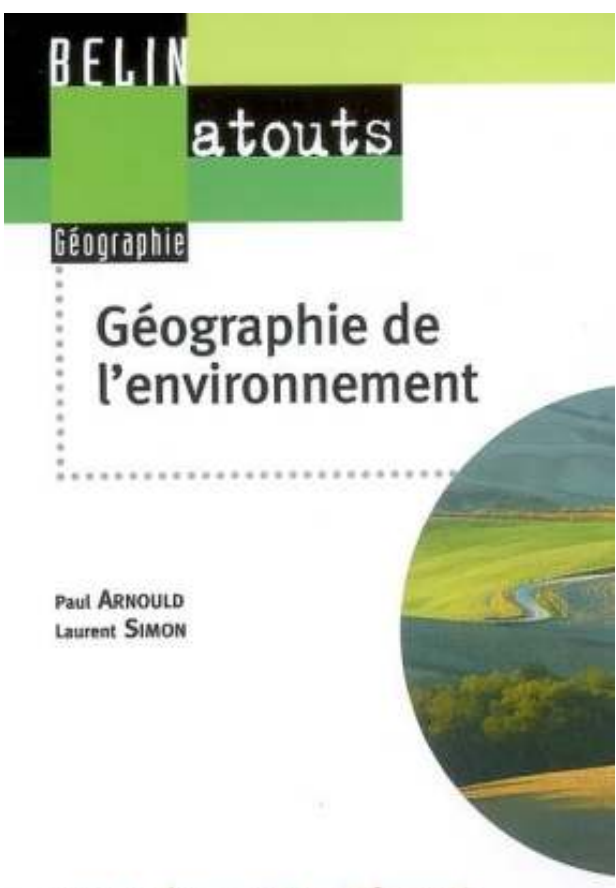

• cours • documents • entraînement nature, aménagement et sciences de l'homme. Ils invitent encore à relier les échelles spatiales emboîtées et les échelles de temps longs historicisés, rompus, accélérés, marqués par la récente montée en puissance des droits de l'environnement.

2 L'ouvrage obéit à un cahier des charges didactique précis. Sa partition distingue les savoirs (8 leçons) et les savoir-faire (6 dossiers). Ce cadrage permet de faire des choix, de privilégier des éclairages, de jouer sur les échelles et les complémentarités entre les études de cas développées et qui peuvent être lues séparément. Le tout est abondamment illustré, avec de la diversité dans les supports utilisés et des renvois dans le texte à des références bibliographiques pour l'essentiel très actualisées. Chaque première page de chapitre dresse un résumé problématisé et énonce des prolongements possibles à mener. Ceci fait du livre un outil intelligent, une invitation à rebondir voire agir comme éco-citoyen. Ces questions sont par exemple : «Peut-on isoler des espaces pour les protéger?» (p. 131) ou encore «Les espaces de faible biodiversité : des espaces sans intérêt ?»(p. 155). Les chapitres traités font la liste des grands problèmes actuels identifiés; en particulier le réchauffement, l'érosion des formes de biodiversité, les dégâts causés par la déforestation, etc. Ces textes incluent toujours dans leur développement un volet original, atypique ou peu connu, marqueur d'une autre histoire qui invite à la modestie dans notre compréhension de la noosphère. C'est la question de la perte de biodiversité confrontée à la géopolitique, le désert associé aux barrages verts porteurs d'espoir pour le Sahel, les polémopaysages retenus comme illustration du laminage ou de la fragilité des sols des champs de bataille.

3 Les savoirs sont éclairés par l'exposé de six dossiers. Il s'agit d'études de cas thématiques (les espaces verts urbains), d'études linéaires (l'eau du Rhône à Barcelone) ou de sujets traités à l'échelle de grandes régions (les contradictions de la conservation en Australie). Ces travaux fournissent des éclairages sur l'utilisation de la ressource, sa transmission, les effets de domino qui peuvent se produire ; bref la complexité de la 
gestion dynamique holiste du vivant. Ainsi, le dossier relatif aux espaces verts urbains s'attache çà la fois à poser les limites de la ville et la part mesurable de la nature dans la façon de vivre ensemble et à conforter des formes de réseau et de connexité dans la ville. Cette analyse est étayée par deux éclairages : la rupture formée par la forêt de Bondy par rapport aux grands ensembles de Montfermeil ou encore les jardins partagés en position interstitielle dans le tissu urbain parisien.

4 Au final, ce livre riche et didactique renouvelle les approches environnementalistes associées à la discipline géographique et ses enseignements. 